\title{
Flight periodicity and the vertical distribution of high-altitude moth migration over southern Britain
}

Article

Published Version

Copyright Cambridge University Press

Wood, C. R., Reynolds, D.R., Wells, P.M., Barlow, J. F., Woiwod, I.P. and Chapman, J.W. (2009) Flight periodicity and the vertical distribution of high-altitude moth migration over southern Britain. Bulletin of Entomological Research, 99 (05). pp. 525-535. ISSN 0007-4853 doi:

https://doi.org/10.1017/S0007485308006548 Available at https://centaur.reading.ac.uk/1573/

It is advisable to refer to the publisher's version if you intend to cite from the work. See Guidance on citing.

Published version at: http://dx.doi.org/10.1017/S0007485308006548

To link to this article DOI: http://dx.doi.org/10.1017/S0007485308006548

Publisher: Cambridge University Press

Publisher statement: Copyright of Cambridge University Press

All outputs in CentAUR are protected by Intellectual Property Rights law, including copyright law. Copyright and IPR is retained by the creators or other copyright holders. Terms and conditions for use of this material are defined in the End User Agreement. 


\section{CentAUR}

Central Archive at the University of Reading

Reading's research outputs online 


\title{
Flight periodicity and the vertical distribution of high-altitude moth migration over southern Britain
}

\author{
C.R. Wood ${ }^{1,2 *}$, D.R. Reynolds ${ }^{3}$, P.M. Wells ${ }^{2}$, J.F. Barlow ${ }^{1}$, \\ I.P. Woiwod ${ }^{2}$ and J.W. Chapman ${ }^{2}$ \\ ${ }^{1}$ Department of Meteorology, University of Reading, Earley Gate, Reading, \\ RG6 6BB, UK: ${ }^{2}$ Rothamsted Radar Entomology Unit, Plant and \\ Invertebrate Ecology Department, Rothamsted Research, Harpenden, \\ Hertfordshire, AL5 2JQ, UK: ${ }^{3}$ Natural Resources Institute, University of \\ Greenwich, Central Avenue, Chatham, Kent, ME4 4TB, UK
}

\begin{abstract}
The continuous operation of insect-monitoring radars in the UK has permitted, for the first time, the characterization of various phenomena associated with highaltitude migration of large insects over this part of northern Europe. Previous studies have taken a case-study approach, concentrating on a small number of nights of particular interest. Here, combining data from two radars, and from an extensive suction- and light-trapping network, we have undertaken a more systematic, longer-term study of diel flight periodicity and vertical distribution of macro-insects in the atmosphere. Firstly, we identify general features of insect abundance and stratification, occurring during the 24-hour cycle, which emerge from four years' aggregated radar data for the summer months in southern Britain. These features include mass emigrations at dusk and, to a lesser extent, at dawn and daytime concentrations associated with thermal convection. We then focus our attention on the well-defined layers of large nocturnal migrants that form in the early evening, usually at heights of $200-500 \mathrm{~m}$ above ground. We present evidence from both radar and trap data that these nocturnal layers are composed mainly of noctuid moths, with species such as Noctua pronuba, Autographa gamma, Agrotis exclamationis, A. segetum, Xestia c-nigrum and Phlogophora meticulosa predominating.
\end{abstract}

Keywords: insect layers, aerial migration, entomological radar, noctuid moths, flight periodicity

(Accepted 20 September 2008)

\section{Introduction}

Most insects migrate at altitudes of a few hundred metres up to about two kilometres above the ground (Glick, 1939; Johnson, 1969; Gatehouse, 1997), well above their 'flight boundary layer' - a (normally) shallow layer of the

*Author for correspondence

Fax: +44118 3788905

E-mail: c.r.wood@reading.ac.uk atmosphere extending up from the ground where the wind speed is less than an insect's air speed (Taylor, 1974). Insects flying at altitude should be regarded as active migrants because they have to sustain wing-beating to stay aloft (see below) and, due to the fast wind speeds usually encountered at these heights, they are capable of traversing tens or even hundreds of kilometres in just a few hours' flight (e.g. Chapman et al., 2002a, 2008). Due to the difficulties inherent in observing small organisms at comparatively high altitudes, insects flying here are less widely studied than those flying near the ground. Nonetheless, many important insect 
pests are high-altitude migrants (Pedgley, 1982, 1993; Drake \& Gatehouse, 1995; Reynolds et al., 2006); and it is, therefore, important that we gain a good understanding of their flight behaviour and its consequences.

Radar has been used to measure density-height profiles of migrating insects at many sites around the world, and some consistent patterns have been revealed (Drake, 1984; Drake \& Farrow, 1988; Drake \& Rochester, 1994; Gatehouse, 1997; A.M. Reynolds et al., 2008). One frequently observed distribution is the concentration of insects into layers of great horizontal spatial extent, but restricted depth $(\sim 50-200 \mathrm{~m})$, which often persist for several hours. These layers seem to be formed by insect migrants ascending after take-off (or perhaps descending later in their migratory journey), reaching particularly favourable attitudes and then maintaining flight there. Intense layering is particularly common when insects are migrating under the stable atmospheric conditions that exist in and above the night-time atmospheric boundary layer (ABL) during fair weather. In such conditions, insects apparently have excellent control over their flight altitude due to the weak vertical atmospheric motions (Wood et al., 2006). Under these circumstances, insect migrants apparently select favourable altitudes at which to fly, such as in the zone of warmest air found at the top of a temperature inversion (which may facilitate prolonged flight if air temperatures are sub-optimal at other altitudes). In other cases, migrants may select the altitude of a nocturnal wind jet (thus maximising migration distances), which presupposes that they can somehow detect the presence of such wind-speed maxima (A.M. Reynolds et al., 2008).

Until now, most investigations of layering, both in the UK (D.R. Reynolds et al., 2005, 2008; Wood et al., 2006) and elsewhere (Drake \& Farrow, 1988; Drake \& Rochester, 1994; Gatehouse, 1997; Feng et al., 2003, 2004, 2005), have been case studies of just one or a few nights only. However, to gain a clear picture of the frequency and scale of insect layering, and an understanding of the factors underlying layer formation, it is necessary to analyse data from long-term studies of insect density profiles. The only practicable way such data can be collected is by autonomously-operating entomological radar systems that provide continuous monitoring of aerial insect populations. We have been running such a system, comprising two vertical-looking entomological radars in southern UK, that has provided continuous data on vertical profiles of insect density since 1999 (Chapman et al., 2003).

In this paper, we take the first step towards producing a 'climatology' of insect layering at night (sensu Drake \& Rochester, 1994) by providing quantitative answers to the following questions: (i) at what times of the day/night and at what altitudes do macro-insects fly? (ii) At what times and altitudes do intense layers of macro-insects most frequently occur? (iii) Which species are the most prevalent constituents of the nocturnal layers observed over the UK? Lastly, we aim to confirm that the nocturnal layers are due to active selection of flight height by the migrants and that they are not formed 'passively' due to the concentration of insects by atmospheric motion alone.

Radar studies elsewhere have frequently shown that the primary constituents of observed nocturnal layers are migratory noctuid moths, which are important agricultural pests (e.g. Chen et al., 1989; Wolf et al., 1990; Feng et al., 2003, 2005); and this is potentially the case in the present study. Climate change seems likely to increase the frequency of lepidopteran migration into Britain (Sparks et al., 2007), and a greater understanding of the mechanisms of flight-altitude selection by these migrants will be essential for the development of predictive models of pest immigration and outbreak management.

\section{Materials and methods \\ Vertical-looking entomological radar}

Continuous measurements of vertical profiles of insect abundance were obtained from two vertical-looking insectmonitoring radars (VLRs) (Chapman et al., 2003) situated at Malvern (Worcestershire) in west-central England, and at Harpenden (Hertfordshire) in east-central England (see details in D.R. Reynolds et al., 2008). The VLRs provide instantaneous vertical profiles in terms of (i) the number of individual targets, (ii) aerial density and (iii) a measurement of multi-target biomass (this is useful when densities are too high for individual targets to be resolved). Here, we are mainly considering macro-insect targets, with a mass greater than $15 \mathrm{mg}$, which were detected over the full height range of the radars ( $150 \mathrm{~m}$ to $1.2 \mathrm{~km}$ above VLR). In this study, we analysed the data collected by both radars during the summer months (June-August) of four consecutive years (2000-2003, inclusive). Full details of the radars' operation are described elsewhere (Chapman et al., 2002b, 2003; D.R. Reynolds et al., 2005, 2008), and the following is therefore a brief summary.

Return signals were recorded from individual insect targets flying through one of the fifteen 'range-gates' (the sampling volumes), each of which are $45 \mathrm{~m}$ deep, separated by a $26 \mathrm{~m}$ non-sampled interval. Coverage above the radar was $180-1218 \mathrm{~m}$ at Malvern radar and $150-1188 \mathrm{~m}$ at Harpenden. Data were recorded during five-minute sampling periods, repeated every 15 minutes, 24 hours per day, thus producing 96 vertical profiles per day (or over a million remotely sensed aerial samples during the study period). Several parameters were extracted routinely from the raw data by the analysis program (Smith et al., 1993; Chapman et al., 2002b) - particularly horizontal speed, displacement direction, body alignment and three radar back-scattering terms from which body mass and body shape are estimated.

The minimum detectable mass varies with altitude, such that a one-milligram insect barely registers in the lowest radar range-gate. This means that micro-insects, such as tiny Diptera, aphids and parasitic Hymenoptera, known to be hugely abundant at these heights (Chapman et al., 2004), are not detected. In Britain, the only insect orders that contain relatively abundant representatives of the migrant fauna, and which are large enough for detection by the radars throughout the sampling range, are certain families of the Lepidoptera, Coleoptera, Neuroptera and Diptera.

\section{Layer classification schemes}

Previous case-study approaches for nocturnal layering events detected by the radars used a layer quality (LQ) classification scheme (see Reynolds et al., 2005). Briefly, this consisted of seven possible categorizationes for each profile, the most pertinent to the present case being: LQ4 (a weak layer), LQ5 (an intermediately-pronounced layer), LQ6 (a pronounced layer) and LQ7 (a possible layer in conditions 
where high insect densities cause considerable inter-target interference).

In the present study, the above classification scheme was extended to produce a new aggregate index, the nocturnal layer quality (NLQ), which could represent the layer quality for a particular night (Wood, 2007). To calculate the NLQ, the mean of all LQ values of 4,5 and 6 was taken for the period 21:00-23:50 $\mathrm{h}$ UTC (all times in this paper are in UTC) resulting in a single value for 12 early evening profiles. NLQ values have a range between 0 and 6 . If $L Q=6$ for all 12 profiles, then a value of $N L Q=6$ is returned; if LQ does not equal 4,5 or 6 in any of the 12 profiles, then a value of $\mathrm{NLQ}=0$ is returned. Mid-range NLQ values can, therefore, be produced either by temporally persistent layers of weak/ intermediate sharpness or by very pronounced, but shortlived, layers.

\section{Insect trapping}

Data from the Rothamsted Insect Survey's (RIS) UK-wide light-trap and suction-trap network (Woiwod \& Harrington, 1994) were used to ascertain which species of large nocturnally-migrating insects (in effect, noctuid moths) were most likely to be involved in the formation of nocturnal layers. The RIS light-trap network consists of standard Rothamsted traps (each fitted with a $200 \mathrm{~W}$ tungstenfilament (non-UV) light bulb: Williams, 1948) distributed throughout the UK, which are emptied on a daily basis. For the purposes of this study, all the noctuids caught by all the RIS traps in England and Wales ( 60 traps in use per year) during 2000-2006, inclusive, were identified to species. The RIS suction-trap network consists of towers $12.2 \mathrm{~m}$ tall that sample the insects flying directly above them (Macauley et al., 1988). The aphid portion of the samples are routinely extracted and identified, while all the other insects are stored in alcohol. For the purposes of this study, we had access to data on the identity and abundance of all the noctuid moths from the stored samples from 12 suction-traps distributed throughout England for the three years 2001, 2006 and 2007.

The fresh body weight and wing length (defined as thoracic centre to wing-tip) were measured for a range of moth species caught in a mercury-vapour (MV) light-trap at Rothamsted between 1999 and 2001. These measurements were required for comparison with radar-target-size distributions and for estimates of terminal velocities (see below).

We also attempted to identify the macro-insects detected by the radar directly by means of aerial trapping at $200 \mathrm{~m}$ above ground level (AGL) using a net suspended from the tethering line of a helium-filled blimp (Chapman et al., 2004). This work was carried out at Cardington airfield, Bedfordshire, approximately $40 \mathrm{~km}$ north of the Harpenden radar, for several weeks each summer during 1999-2007, inclusive. As the aerial net has a small aperture $\left(0.64 \mathrm{~m}^{2}\right)$, the method is more suited to sampling of small insects; but, when macro-insects are caught, this is indicative of very large numbers being airborne (e.g. Chapman et al., 2008).

\section{Terminal velocities}

If the insects were to free-fall when they stopped flying, estimates of their terminal velocity $\left(w_{T}\right)$ will give some idea of how quickly a layer would be expected to dissipate. A basic fluid mechanic model was used to calculate fall speed (see Maryon, 1997; Wood, 2007), with mass and insect cross-sectional area being the required variables. The crosssectional area of the falling insect was calculated for the open- and closed-wing condition.

\section{Results \\ Diel periodicity of insect activity}

Daily patterns of insect activity at high altitudes throughout the study period were examined in detail, and some typical features of the vertical profile in insect numbers can be seen in the example (for 16 June 2000) presented here (fig. 1). Peaks of flight activity, particularly at the lowest altitudes covered by the radars, occurred around dawn (ca. 03:00-04:00) and dusk (ca. 20:00-22:00), associated with the synchronised take-off of large numbers of migrants (see also D.R. Reynolds et al., 2005, 2008; Wood et al., 2006). As many as 70 macro-insect targets were detected per rangegate in a five-minute sample at this time.

Substantial dusk emigration in the summer quite often leads to the formation of layers aloft as the migrants ascend to particular altitudes and maintain flight there for extended periods of the night (Reynolds et al., 2005; Wood et al., 2006). Generally, in the UK, the 'ascent phase' profiles (which often show a semi-logarithmic decline in insect numbers with height) evolve directly into a nocturnal layering profile with a well-defined density maximum at a specific height. On this particular occasion (fig. 1), however, many of the dusk-only (crepuscular) fliers evidently descended back to the surface before the nocturnal layering event developed. Soon after 22:00 h, however, sample numbers reached 20-50 targets per range-gate at $\sim 200-300 \mathrm{~m}$ AGL as an elevated layer formed. The layer rose steadily until, at midnight, it was centred at $\sim 600 \mathrm{~m}$ AGL, where it persisted until dawn on 17 June. This occasion was somewhat unusual in that the migrants forming the layer flew all night, but moderately pronounced layering (see below) occurred on $30 \%$ of nights of the study period.

The other obvious feature in fig. 1 is the large amount of insect activity that occurred through the daytime, from 09:00 onwards. Daytime profiles of insect numbers varied considerably over both height and time - targets were present up to about $800 \mathrm{~m}$, although the greatest counts were generally at the lowest observable altitudes. This build-up of insect activity was very probably associated with convective plumes in the daytime ABL (Drake \& Farrow, 1988; Geerts \& Miao, 2005; D.R. Reynolds et al., 2008).

Using data from the pooled four-year radar dataset, the mean number of insect targets per altitude band was plotted for the 736 summertime 24-h periods (fig. 2). The key difference between the example in fig. 1 and the pooled data displayed in fig. 2 is that, due to the absence of a consistent height for the nocturnal layering, this feature is not evident in the mean pattern; in fact, the greatest insect densities always occurred at the lowest observable heights.

The greatest numbers of insect targets during the 24-h period occurred during the dusk migration peak (mean of up to $\sim 24$ targets), while the lowest numbers occurred late in the night (about 01:00-02:30). The dawn activity peak was visible, but considerably less intense than the dusk one. Daytime activity generally started to build up between 06:00 and 07:00, although the largest numbers of daytime targets were observed between 11:00 and 14:30. 


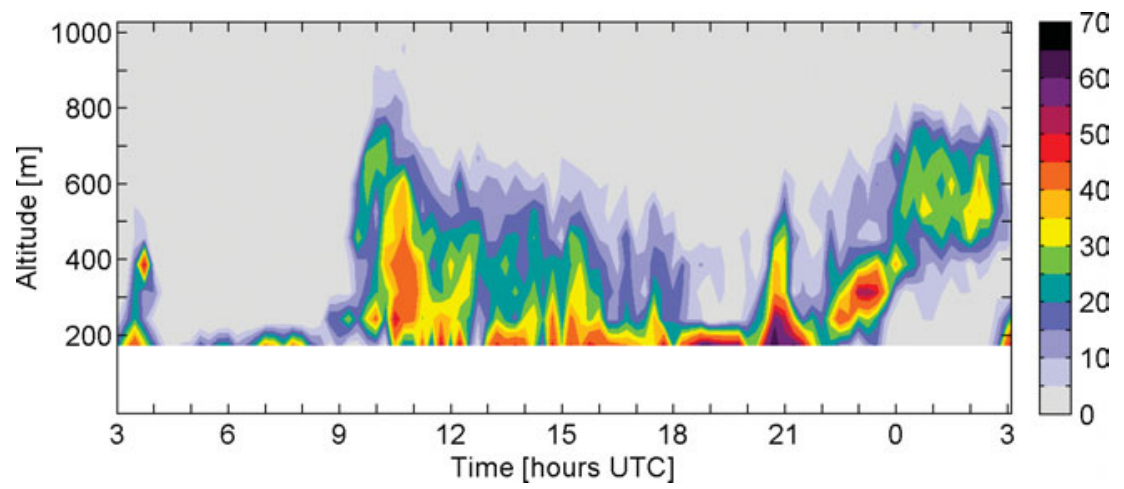

Fig. 1. Time/height plot of insect numbers detected in a five-minute sample (see colour key) taken every 15 minutes on $16-17$ June 2000 on the Malvern radar. This 24-h period shows many of the typical features in the vertical profile (see text). On 16 June, the end of civil twilight and sunrise were at 02:59 and 03:48, respectively; sunset and the end of civil twilight were at 20:31 and 21:20, respectively. No data was available for heights below $150 \mathrm{~m}$ above the radar.

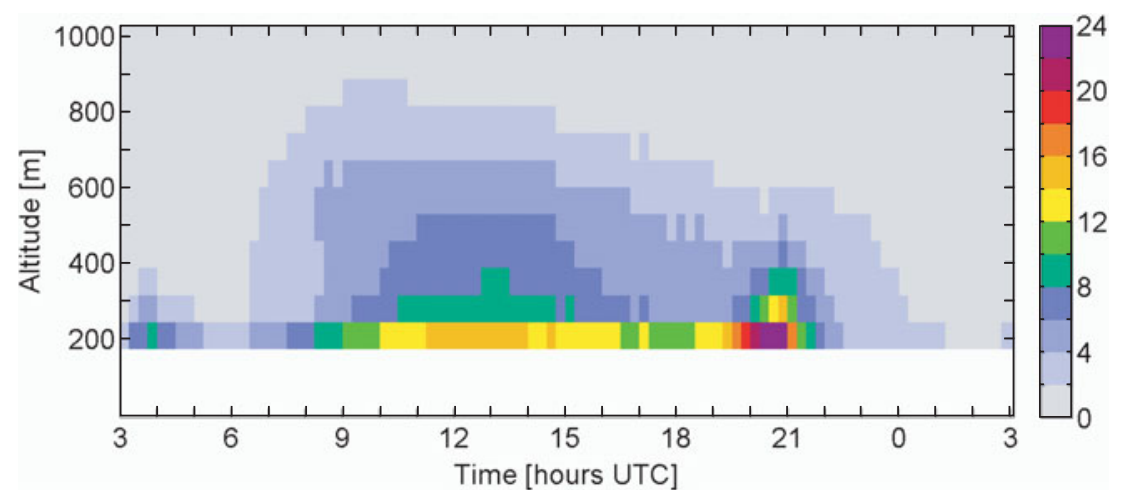

Fig. 2. Time/height plot of insect numbers per five-minute sample (see legend for fig. 1), showing the pooled mean data for JuneAugust 2000-2003, inclusive, for both the Malvern and Rothamsted radars. No interpolation was used for the contours.

The greatest heights reached by insects occurred during the daytime (e.g. the 'two target' isopleth reached up to $850 \mathrm{~m}$ AGL between 09:00 and 10:00 (fig. 2)). At this time, air temperature constraints on flight height will be less severe than at night, and the ascent of many insects will be assisted by turbulent updraughts associated with the daytime convective boundary layer. The equivalent height was only $400 \mathrm{~m}$ for the dawn peak and $600 \mathrm{~m}$ for the dusk peak. The rate of decrease with altitude of insect numbers was greater at dusk than during the day.

Summation of insect numbers over all flight heights (fig. 3) clearly shows three of the four diurnal flight phases (i.e. dawn, daytime and dusk), but nocturnal activity is comparatively low. Of the months shown, July had the greatest daytime aerial activity and June the least. The mean maximum temperatures at screen level (ca. $1.5 \mathrm{~m}$ AGL) in the Midlands of the UK (UK Met Office website) were $19.3 \pm 1.1^{\circ} \mathrm{C}$ (95\% C.I.), $20.7 \pm 1.1^{\circ} \mathrm{C}$ and $21.7 \pm 0.9^{\circ} \mathrm{C}$ for June, July and August, respectively. The coolest month (June) had the least flight activity in the middle of the day, while July and August with rather similar maximum temperatures had considerable overlap in daytime activity values. Presumably, other factors, such as timing of adult emergence and migration from continental Europe, may also influence the month-by-month variations in addition to the direct effect of temperature on flight activity.

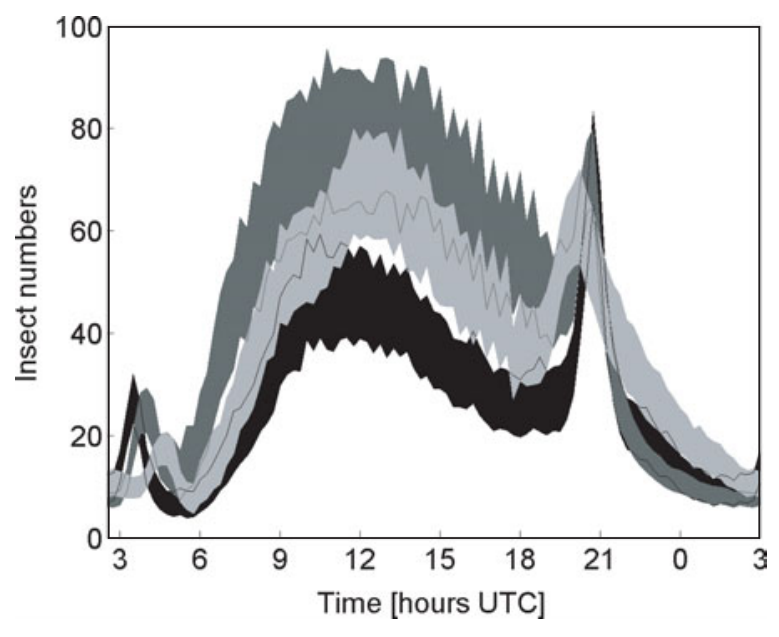

Fig. 3. Confidence intervals (95\%) for the total insect numbers in radar sampling profile (for every 15-minute interval throughout the 24-h period) for the months of June, July and August, averaged over the years 2000-2003, inclusive, for both radars (ם, June; $\square$, July; $\square$, August). 


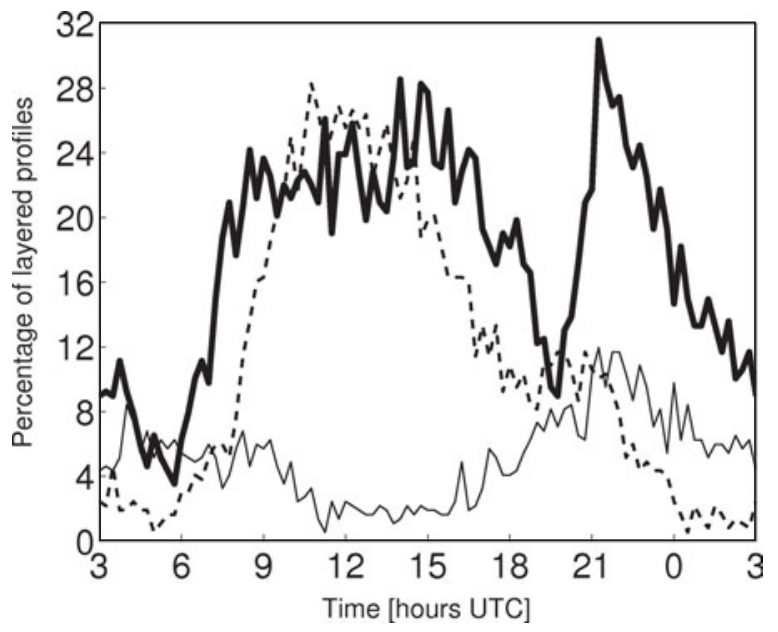

Fig. 4. Layering occurrence (\%) in each 15-minute time interval throughout the 24-h period for June-August 2000-2003, inclusive, for both radars. Layer quality $(\mathrm{LQ}=4,5$ or 6$)$ values indicate layers of increasing intensity (see text) $(---, \mathrm{LQ}=4$; -, LQ=5; -, LQ=6).

The daytime maximum in total insect numbers apparently occurred at 10:00-13:00 (fig. 3), before the part of the day that is usually the warmest (typically 12:00-15:00), but caution is required here because high levels of inter-target interference during very high-density insect activity may produce an apparent drop in analysable signals (Chapman et al., 2002b).

The dusk peak had very similar numbers of insect targets in June and July, but there was a slight reduction in August (mean $\sim 70$ targets). The progression of the timing of the dusk and dawn peaks towards mid-day from June to August illustrates the dependence of the peaks' timing on illumination (since the time of sunset and sunrise move closer to midday once the summer solstice has passed). This result thus indicates that the dawn and dusk activity peaks are initiated and terminated by particular light intensity thresholds that are reached progressively later in the morning, and earlier in the evening, as the season advances (Lewis \& Taylor, 1964).

Finally, we note that nighttime insect activity (after the dusk peak) is increased in August compared with June and July (fig. 3). The mean minimum temperatures at screen level (ca. $1.5 \mathrm{~m} \mathrm{AGL)} \mathrm{in} \mathrm{the} \mathrm{Midlands} \mathrm{of} \mathrm{the} \mathrm{UK} \mathrm{(UK} \mathrm{Met} \mathrm{Office}$ website) were $9.9 \pm 0.7^{\circ} \mathrm{C}(95 \%$ C.I. $), 11.5 \pm 0.9^{\circ} \mathrm{C}$ and $12.0 \pm$ $0.5^{\circ} \mathrm{C}$ for June, July and August, respectively. There was thus no overlap in the confidence intervals for mean minimum temperatures for June compared with the warmer August nights, which may at least partly explain why there was greater nocturnal activity during August (fig. 3).

\section{Periodicity of layering}

The proportion of layering profiles in each LQ category that occurred throughout the day/night is shown in fig. 4. Weak and intermediate layers $(\mathrm{LQ}=4$ or 5$)$ were very frequent during the daytime. Examination of daily profiles indicates that some of this apparent layering was probably an artefact caused by multi-target 'saturation' effects reducing target numbers and resulting in gaps in the profile. In

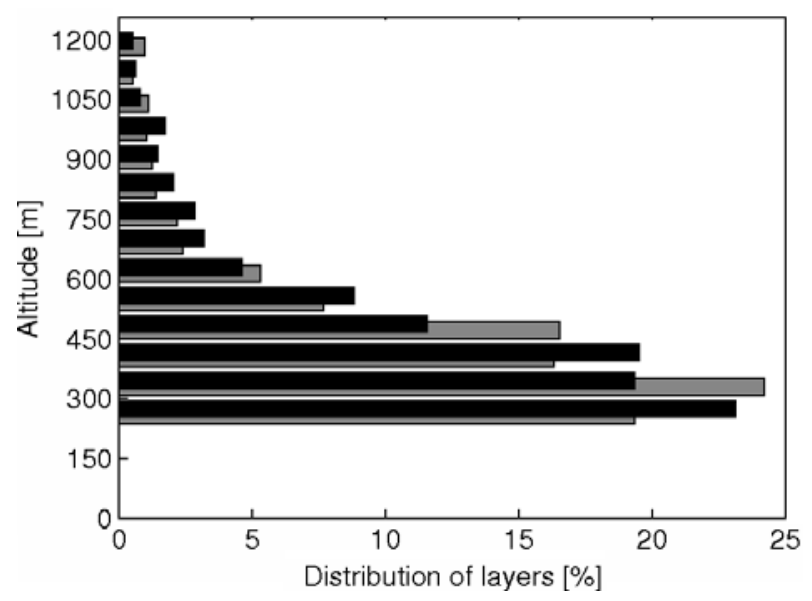

Fig. 5. Altitude at which nocturnal (21:00-23:50 hours UTC) layers occur in the pooled data for June-August 2000-2003, inclusive, for both radars. See text for definition of a layer ( $\square$, Malvern; $\square$, Rothamsted).

contrast, the analysis showed that nocturnal layers were more intense and stable than daytime 'layers', because LQ values of 5 and 6 peaked at night. The peak for both the intermediate and strong layers (30\% and 11\% for LQ values of 5 and 6 , respectively) occurred at $\sim 21: 15$, soon after the dusk activity peak. In fact, at $21: 15,60 \%$ of the profiles showed some degree of layering (defined as having an LQ value of 4-7), and layers became less common after this time. For the remainder of this study, we focus on the persistent and relatively stable nocturnal layers.

\section{The altitude of nocturnal layers}

For occasions when nocturnal layering was present (defined here as NLQ $>1$, which occurred on $30 \%$ of nights), the pooled vertical distribution data were examined to determine whether there was a preferential altitude for layering. Figure 5 shows that around three quarters of nocturnal layers detected by the radars $(76 \%$ at Malvern, $73 \%$ at Rothamsted) occurred in range-gates 2-5, i.e. below $500 \mathrm{~m}$ AGL. (By definition, a layer cannot occur in range-gate 1 because layers are only recognised when there are reduced numbers in the gates both above and below it.) The peak in layering occurred in range-gate 3 (ca. $300 \mathrm{~m} \mathrm{AGL)} \mathrm{at}$ Malvern. However, at Rothamsted, most layering occurred at the lowest observable altitude (range-gate 2, ca. $240 \mathrm{~m}$ AGL).

For the purposes of our study, a 'critical region' for the initiation of summertime nocturnal layers in Britain was, therefore, defined as occurring at: (i) altitudes between 200 and $500 \mathrm{~m}$ AGL, and (ii) times from 20:00-22:00. The meteorological conditions around 20:00, when many migrants are commencing flight, will be crucial in determining if a layer will be initiated or not. The end of the critical period was designated as 22:00, when the dusk peak will be long past and any layer going to develop will probably have formed. Thus, future research on the initiation of nocturnal insect layers could usefully be focused on this critical region. 


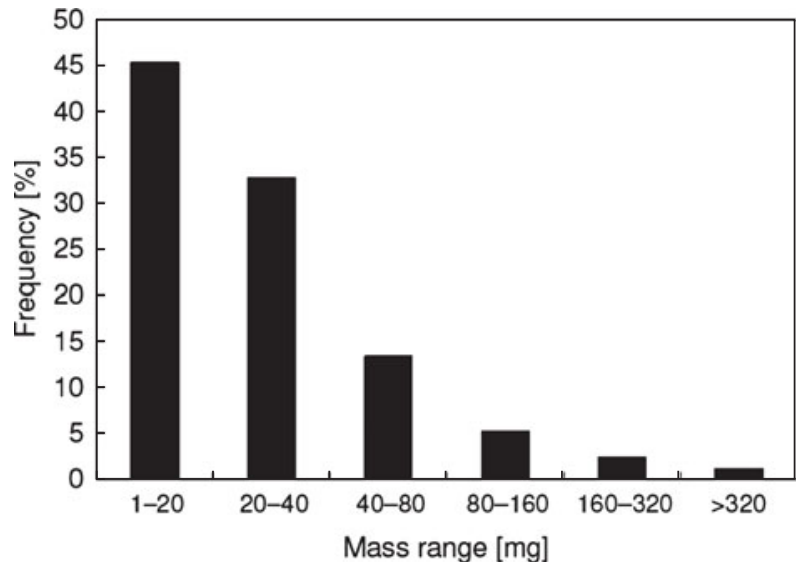

Fig. 6. Mass distributions of insects detected at all radar sampling heights, for all times of the day and night, during the months of June-August 2000-2003, inclusive, at both radar sites. Insects of mass below $\sim 1 \mathrm{mg}$ are not detected by the radar (see text).

\section{Identity of species in nocturnal layers}

Identification of radar-detected insects to species level can sometimes be achieved if ground-based trap data, or preferably high-altitude netting data (Chapman et al., 2004), are available to complement the analysis and provide an indication of the most likely candidate species (e.g. Chapman et al., 2002a, 2005, 2006, 2008; Wood et al., 2006). In the type of general analysis presented here, it is impossible to identify the majority of radar-detected insects to species level; but certain subsets of radar targets can, perhaps, be narrowed down to particular taxonomic groups, such as 'noctuid moths' (Lepidoptera: Noctuidae) or 'green lacewings' (Neuroptera: Chrysopidae). The first step is to compare radar target mass distributions with the masses of insect taxa known (from, say, trapping evidence) to be flight active at the relevant season and time of day. Figure 6 shows the frequency distribution of insect mass for all radar-detected insects (day-flying and nocturnal) during the summer months of 2000-2003 at both sites. As expected from aerial trapping evidence, there is a clear reduction in insect abundance as body mass increases, at least for the mass range shown here. It should be noted that the radar only detects insects larger than $\sim 1 \mathrm{mg}$ and that targets weighing a few milligrams are likely to be under-sampled (Smith et al., 2000; Wood et al., 2008 unpublished data). Therefore, the dominance of the small day-flying insects will be, if anything, underestimated. By comparison, the mass distribution of night-flying insects during the same sample period is quite different, with the maximum abundance in the $80-160 \mathrm{mg}$ size class (fig. 7). Leaving aside the uncertainties of undersampling in the smallest size category $(1-20 \mathrm{mg})$, it is very clear that large insects are proportionally much more abundant at night than during the day; and thus these large nocturnal insects are a major constituent of the nocturnal layers discussed here.

Since virtually the only large nocturnal insects caught at high-altitude in the UK are noctuid moths (Chapman et al., 2004, 2008, and unpublished data), the rest of the analysis in this study will focus on this family. Table 1 lists the 25 most abundant species caught in the RIS national light-trap network during 2000-2006. It contains the well-known

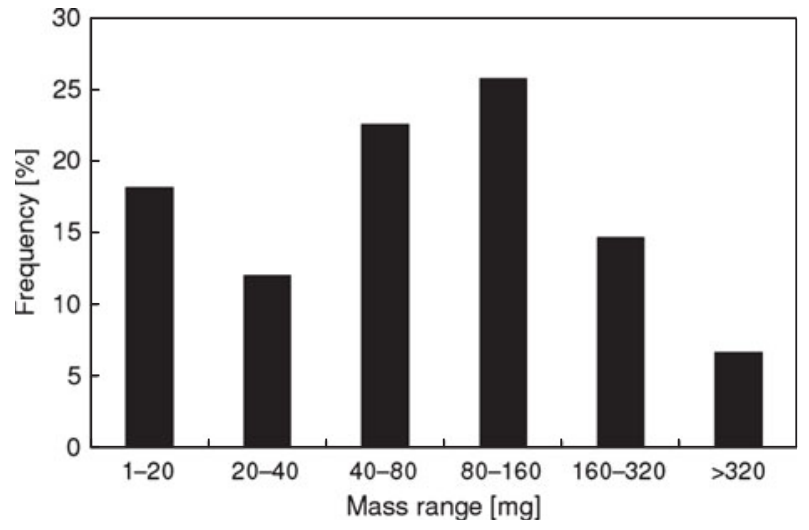

Fig. 7. Mass distributions of insects detected at all radar sampling heights at night (defined as from one hour after sunset until one hour before sunrise) for the months of June-August 2000-2003, inclusive, at both radar sites.

long-distance obligate migrant, Autographa gamma, and some resident species that are facultative migrants, such as Noctua pronuba and Xestia c-nigrum. The light-trap results are likely to reflect abundance rather than migration tendency; so, to determine which of these abundant species are most likely to be ascending to higher altitudes, we examined abundance data for noctuid moths caught in the $12.2 \mathrm{~m}$ suction-trap network and tabulated the 25 most abundant species (table 2) (see also Lewis \& Taylor, 1964, p. 444). The most common species, Amphipyra tragopoginis, is not migratory and its capture in large numbers at $12.2 \mathrm{~m}$ is curious, but it seems unlikely that it engages in high-altitude movement. (Taylor \& Carter (1961) found a continuously diminishing density with height, up to at least $17 \mathrm{~m}$, in this species.) However, some of the other abundant species in the suction trap, such as N. pronuba, A. gamma, Agrotis exclamationis, X. c-nigrum, Phlogophora meticulosa and Agrotis segetum are known, or are strongly suspected, to be migratory (see Discussion). In these cases, capture at $12.2 \mathrm{~m}$ is consistent with migratory individuals ascending above their 'flight boundary layer' and potentially engaging in long-distance transport on the wind. Moth species with these characteristics are likely to be the dominant species in the layers.

The mean body mass and wing length of noctuid moth species that are known to be migrants or were common in both suction-trap and light-trap catches are shown in table 3 . The mass estimates of these migratory species are quite consistent with the mass distribution of large nocturnally-flying targets derived from the radar data, as discussed below.

\section{Insect sizes and terminal velocities}

Figure 8 shows the relationship between body mass and wing-length for 209 individuals (of 17 noctuid species). The linear regression is given by:

$$
m=20.9 l_{w}-215
$$

where $m$ is the mass of a noctuid moth, in $\mathrm{mg}$, and $l_{w}$ is length of wing, in $\mathrm{mm}\left(\mathrm{R}^{2}=78 \%, \mathrm{P}<0.001\right)$.

Values of cross-sectional area and insect mass were found to be closely correlated (for closed wings: $\mathrm{R}^{2}=74 \%, P<$ 0.001 ), and hence cross-sectional area can be estimated from 
Table 1. Summary of the catches of the 25 most abundant species of noctuid moth, from all English and Welsh RIS light-traps (ca. 60 traps in use per year) during 2000-2006, inclusive.

\begin{tabular}{|c|c|c|c|c|c|}
\hline & Species & Common name & $\begin{array}{l}\text { Mean number } \\
\text { caught per year }\end{array}$ & S.E. & Proportion $\dagger$ \\
\hline 1 & Rivula sericealis & Straw Dot & 4045 & \pm 853 & $8.7 \%$ \\
\hline 2 & Xestia xanthographa & Square-spot Rustic & 3807 & \pm 656 & $8.2 \%$ \\
\hline 3 & Omphaloscelis lunosa & Lunar Underwing & 3295 & \pm 535 & $7.1 \%$ \\
\hline 4 & Orthosia gothica & Hebrew Character & 3271 & \pm 380 & $7.0 \%$ \\
\hline 5 & Mythimna pallens & Common Wainscot & 2545 & \pm 788 & $5.5 \%$ \\
\hline 6 & Hypena proboscidalis & The Snout & 2543 & \pm 376 & $5.4 \%$ \\
\hline 7 & Luperina testacea & Flounced Rustic & 2532 & \pm 173 & $5.4 \%$ \\
\hline 8 & Noctua pronuba & Large Yellow Underwing & 2392 & \pm 164 & $5.1 \%$ \\
\hline 9 & Xestia c-nigrum & Setaceous Hebrew Character & 2249 & \pm 415 & $4.8 \%$ \\
\hline 10 & Mesapamea didyma & Common Rustic & 1942 & \pm 217 & $4.2 \%$ \\
\hline 11 & Orthosia cruda & Small Quaker & 1889 & \pm 96 & $4.0 \%$ \\
\hline 12 & Conistra vacinii & The Chestnut & 1838 & \pm 243 & $3.9 \%$ \\
\hline 13 & Mythimna impura & Smoky Wainscot & 1664 & \pm 112 & $3.6 \%$ \\
\hline 14 & Diarsia rubi & Small Square-spot & 1544 & \pm 407 & $3.3 \%$ \\
\hline 15 & Ochropleura plecta & Flame Shoulder & 1310 & \pm 184 & $2.8 \%$ \\
\hline 16 & Hoplodrina alsines & The Uncertain & 1257 & \pm 122 & $2.7 \%$ \\
\hline 17 & Apamea monoglypha & Dark Arches & 1165 & \pm 181 & $2.5 \%$ \\
\hline 18 & Oligia spp. & Combined Minor spp. & 1064 & \pm 85 & $2.3 \%$ \\
\hline 19 & Diarsia mendica & Ingrailed Clay & 1014 & \pm 137 & $2.2 \%$ \\
\hline 20 & Agrochola macilenta & Yellow-line Quaker & 990 & \pm 87 & $2.1 \%$ \\
\hline 21 & Herminia griseola & Small Fan-foot & 917 & \pm 97 & $2.0 \%$ \\
\hline 22 & Autographa gamma & Silver Y & 892 & \pm 201 & $1.9 \%$ \\
\hline 23 & Cerapteryx graminis & Antler Moth & 851 & \pm 138 & $1.8 \%$ \\
\hline 24 & Agrotis exclamationis & Heart \& Dart & 829 & \pm 52 & $1.8 \%$ \\
\hline 25 & Cosmia trapezina & Dun-bar & 821 & \pm 136 & $1.8 \%$ \\
\hline
\end{tabular}

$\dagger$ Proportion with respect to the mean numbers of the 25 most abundant species.

Table 2. Summary of the catches of the 25 most abundant species of noctuid moth, from all English RIS suction-traps (11 or 12 traps in use per year) during 2001, 2006 and 2007.

\begin{tabular}{lllccc}
\hline \multicolumn{2}{c}{ Species } & \multicolumn{1}{c}{ Common name } & $\begin{array}{c}\text { Mean number } \\
\text { caught per year }\end{array}$ & S.E. & Proportion $\dagger$ \\
\hline 1 & Amphipyra tragopoginis & Mouse Moth & 124 & \pm 41 & $32 \%$ \\
2 & Noctua pronuba & Large Yellow Underwing & 50 & \pm 11 & $13 \%$ \\
3 & Mesapamea spp. & Common Rustic spp. & 43 & \pm 24 & $11 \%$ \\
4 & Autographa gamma & Silver Y & 25 & \pm 12 & $6.5 \%$ \\
5 & Apamea monoglypha & Dark Arches & 20 & \pm 4.9 & $5.2 \%$ \\
6 & Agrotis exclamationis & Heart and Dart & 18 & \pm 4.1 & $4.6 \%$ \\
7 & Xestia c-nigum & Setaceous Hebrew Character & 15 & \pm 9.3 & $3.8 \%$ \\
8 & Phlogophora meticulosa & Angle Shades & 14 & \pm 1.8 & $3.8 \%$ \\
9 & Mamestra brassicae & Cabbage Moth & 9.0 & \pm 6.1 & $2.4 \%$ \\
10 & Nycteola revayana & Oak Nycteoline & 8.3 & \pm 5.6 & $2.2 \%$ \\
11 & Apamea lithoxylea & Light Arches & 7.3 & \pm 1.9 & $1.9 \%$ \\
12 & Xestia xanthographa & Square-spot Rustic & 7.0 & \pm 0.6 & $1.8 \%$ \\
13 & Agrotis segetum & Turnip Moth & 5.0 & \pm 4.0 & $1.6 \%$ \\
14 & Agrotis puta & Shuttle-shaped Dart & 3.7 & \pm 0.7 & $1.4 \%$ \\
15 & Agrochola litura & Brown-spot Pinion & 3.3 & \pm 0.9 & $1.0 \%$ \\
16 & Apamea crenata & Clouded-bordered Brindle & 3.3 & \pm 0.7 & $0.9 \%$ \\
17 & Mesoligia furuncula & Cloaked Minor & 3.3 & \pm 1.5 & $0.9 \%$ \\
18 & Orthosia gothica & Hebrew Character & 3.3 & \pm 2.8 & $0.9 \%$ \\
19 & Scoliopteryx libatrix & The Herald & 2.7 & \pm 1.7 & $0.9 \%$ \\
20 & Oligia spp. & Minor spp. & 2.7 & \pm 0.9 & $0.7 \%$ \\
21 & Orthosia cerasi & Common Quaker & 2.3 & \pm 0.9 & $0.6 \%$ \\
22 & Hecatera bicolorata & Broad-barred White & 2.0 & \pm 1.2 & $0.5 \%$ \\
23 & Cosmia trapezina & The Dun-bar & 2.0 & \pm 2.0 & $0.5 \%$ \\
24 & Lithophane hepatica & Pale Pinion & 1.7 & \pm 1.7 & $0.4 \%$ \\
25 & Agrochola lychnidis & Beaded Chesnut & & & \\
\hline
\end{tabular}

$\dagger$ Proportion with respect to the mean numbers of the 25 most abundant species. 
Table 3. Mass and wing-lengths of abundant noctuid moth species caught in a mercury-vapour light-trap at Rothamsted, Harpenden, between 1999 and 2001. Listed are the ten species that are most likely to comprise nocturnal layers based on the ranking in both tables 1 and 2 and the reported high migratory propensity of the species (see text).

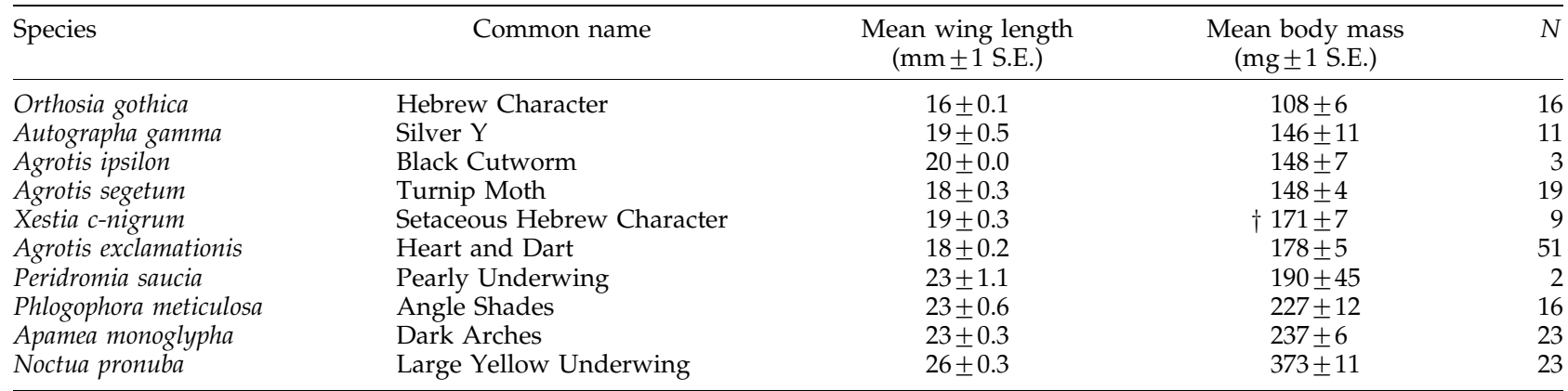

$\dagger$ Fresh masses of this species were not available, the mass value is an estimate based on equation 1 in the 'Results'.

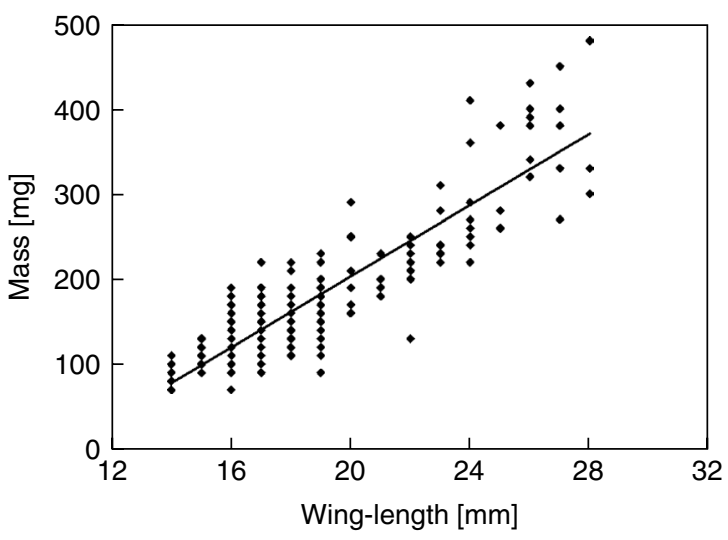

Fig. 8. Body mass against wing-length for 209 noctuid moths of 17 species caught in a mercury-vapour light-trap at Rothamsted during 1999-2001, inclusive.

mass for noctuid moths (Wood, 2007). The terminal velocities $\left(w_{T}\right)$ for a range of noctuid moths were calculated (fig. 9) and found to be $10-12 \mathrm{~m} \mathrm{~s}^{-1}$ if wings were closed and $3-5 \mathrm{~m} \mathrm{~s}^{-1}$ if wings were open. The fitted lines can be used as an approximation to estimate terminal velocity from mass alone:

$$
\begin{aligned}
& w_{T, c}=6.26 m^{0.12} \\
& w_{T, o}=0.92 m^{0.31}
\end{aligned}
$$

for closed and open wings, respectively, where $m$ is mass in mg.

It is clear that the estimated terminal velocities of freefalling insects, of similar size to those comprising the nocturnal layers, are very large compared to the weak turbulent vertical motions that migrants will encounter when flying in the nocturnal atmospheric boundary layer in fair weather conditions (e.g. Stull, 1997; Wood, 2007).

\section{Discussion}

In the current study, we present the first systematic analysis of flight periodicity and altitude-selection in highaltitude migrant macro-insects, using data collected by

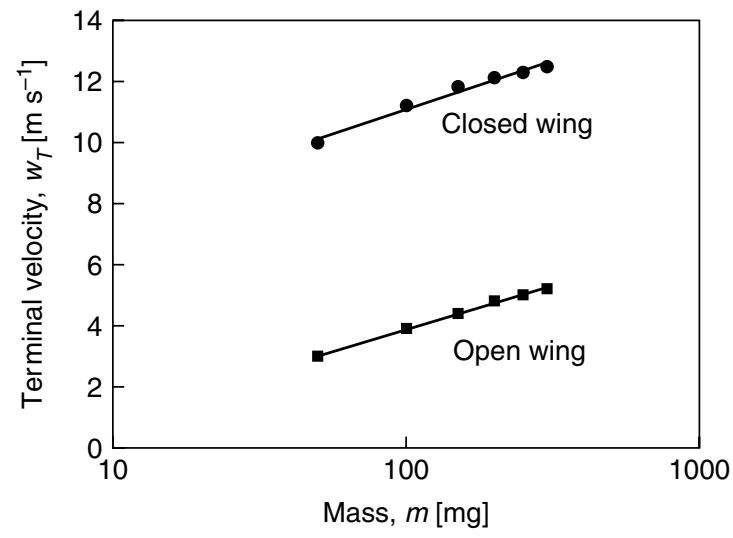

Fig. 9. Terminal velocity (calculated using a simple fluid dynamics model) against moth mass (see text).

continuously-operating insect-monitoring radars in over southern UK during the summer months of four consecutive years.

Daytime layers are reported infrequently in the radar entomology literature compared to nocturnal layers (but note Campistron, 1975; Smith et al., 2000; Chapman et al., $2002 b)$. The daytime layers detected by our radars were not as temporally and spatially continuous as nocturnal layers, probably due to the influence of turbulence and updraughts in the convective boundary layer (Wood, 2007). The processes involved in daytime layering clearly deserve further study; but, in this paper, we have concentrated on the more intense and persistent nocturnal layers.

In summertime in the UK, nocturnal layers were most frequent at 21:15, just after the ubiquitous dusk peak in insect density caused by mass take-off of migrants around dusk (ca. 20:45). This has been previously noted in casestudy analyses (e.g. Reynolds et al., 2005), but the present study has used a much more extensive dataset of archived radar records. Nocturnal layer concentrations tended to dissipate with time later in the night, particularly after midnight when insect aerial densities at all altitudes tend to become very sparse. Hence, although there are occasions in the UK when intense layering persists through the night, these appear to be due to particularly warm temperatures at layer 
altitude (Reynolds et al., 2005) or perhaps to species with long migratory flight durations (Chapman et al., 2008). In the dataset analysed here, the least aerial activity was observed at about 02:30-02:45, following which activity peaked again between 03:30 and 03:45, due to the dawn take-off and emigration. There was a small peak in the frequency of layering at about 04:00, just after (and arising from) the dawn emigration. Dawn layering was generally short-lived; indeed, the period of the day with the least amount of layering was $05: 15$. Case studies of some rather striking and persistent post-dawn layers observed with our insect-monitoring radars are presented in D.R. Reynolds et al. (2008); but these layers are unusual, at least in the UK, and are not considered further here.

Nocturnal layers were observed mostly between altitudes of 200 and $500 \mathrm{~m}$ and were most frequent about $300-400 \mathrm{~m}$ AGL at both locations studied. There remains uncertainty about how much insect layering there was beneath the lowest radar-detection altitude, i.e. below about 150-180 m AGL. Most nocturnal layering followed from mass emigration at dusk (i.e. the dusk peak in insect numbers). Therefore, the 'critical region', in which meteorological variables might have a key influence on nocturnal layer initiation in southern Britain, was defined as the altitude band between 200 and $500 \mathrm{~m}$ AGL during the time period 20:00-22:00 hours. Estimates of terminal velocity show that insects constituting the layers must be maintaining their flight altitude by continuous wing-beating. Thus, nocturnal layers form due to the insects' response to atmospheric conditions, such as zones of warm air temperature or fast winds (Drake \& Farrow, 1988; Reynolds et al., 2005; Wood et al., 2006), and it is clear that they cannot be maintained simply by the action of atmospheric motions alone.

Comparison of the mass distribution of all radar-detected insects (fig. 6) with those detected solely at night (fig. 7) clearly shows that medium and large insects (those $>40 \mathrm{mg}$ ) are much more common at night. As the only insects in this size category that have been caught in our high-altitude aerial netting at night are noctuid moths, we can confidently surmise that this taxon comprises the most important constituent of the nocturnal layers over the UK. The Noctuidae is the most speciose family of the macro-Lepidoptera, with around 400 species in the UK (Chinery, 1993), including some highly abundant species that are long-range migrants in Europe (e.g. Chapman et al., 2008) and other continents (Riley et al., 1983; Fitt, 1989; Showers, 1997; Feng et al., 2003, $2004,2005)$. Two species that were highly abundant in the $12.2 \mathrm{~m}$ suction-trap catches, and that have also been caught flying at $200 \mathrm{~m}$ AGL (Chapman et al., 2004, 2008), were $A$. gamma and N. pronuba. These species are known to be highly migratory (Hill \& Gatehouse, 1993; Howard, 1999; Hächler et al., 2002; Chapman et al., 2008) and so are certain to be abundant constituents of the layers observed in this study. The body mass measurements of these species (table 3) indicate that A. gamma is probably responsible for many of the radar targets in the $80-160 \mathrm{mg}$ size class in years when this species is abundant in Britain, while in other years species such as X. c-nigrum, Agrotis segetum and A. exclamationis may predominate in this size class. $N$. pronuba is probably responsible for the majority of targets in size class $>320 \mathrm{mg}$ (up to about $450 \mathrm{mg}$ ). The intermediate size class of $160-320 \mathrm{mg}$ might well be composed of a number of species, including $P$. meticulosa, the heavier individuals of A. exclamationis, and perhaps Apamea monoglypha. These species have the migratory potential to cover hundreds of kilometres in a single flight (see Wood et al. (2006) for trajectory analyses of noctuid moth flight-paths) and, therefore, can easily fly to the UK from continental Europe. For examples, see Chapman et al. (2008) for the migratory capabilities of A. gamma and French (1969) for the migration of Spodoptera exigua from North Africa to the British Isles. Precise prediction of the heights at which migratory noctuid moths concentrate under particular meteorological conditions will be essential for the production of accurate flight trajectory models, and so systematic studies of the factors involved in the selection of flight altitude will be invaluable for forecasting the migration pathways of pest species.

\section{Acknowledgements}

Some of this work was completed during funding from a BBSRC grant (BBS/S/L/2003/10273). Rothamsted Research receives grant-aided support from the Biotechnology and Biological Sciences Research Council (BBSRC). We thank Met Office staff at Cardington for allowing us to run aerial netting operations on their site, Mr A.D. Smith for comprehensive radar engineering and other technical support, Mr Phillip Gould for identifying the moths and the Rothamsted Insect Survey for trap data.

\section{References}

Campistron, B. (1975) Characteristic distributions of angel echoes in the lower atmosphere and their meteorological implications. Boundary-Layer Meteorology 9, 411-426.

Chapman, J.W., Reynolds, D.R., Smith, A.D., Riley, J.R., Pedgley, D.E. \& Woiwod, I.P. (2002a) High-altitude migration of the diamondback moth Plutella xylostella to the U.K.: a study using radar, aerial netting and ground trapping. Ecological Entomology 27, 641-650.

Chapman, J.W., Smith, A.D., Woiwod, I.P., Reynolds, D.R. \& Riley, J.R. (2002b) Development of vertical-looking radar technology for monitoring insect migration. Computers and Electronics in Agriculture 35, 95-110.

Chapman, J.W., Reynolds, D.R. \& Smith, A.D. (2003) Verticallooking radar: a new tool for monitoring high-altitude insect migration. BioScience 53(5), 503-511.

Chapman, J.W., Reynolds, D.R., Smith A.D., Smith, E.T. \& Woiwod, I.P. (2004) An aerial netting study of insects migrating at high-altitude over England. Bulletin of Entomological Research 94, 123-136.

Chapman, J.W., Reynolds, D.R., Smith, A.D., Riley, J.R., Telfer, M.J. \& Woiwod, I.P. (2005) Mass aerial migration in the carabid beetle Notiophilus biguttatus. Ecological Entomology 30, 264-272.

Chapman, J.W., Reynolds, D.R., Brooks, S.J., Smith, A.D. \& Woiwod, I.P. (2006) Seasonal variation in the migration strategies of the green lacewing Chrysoperla carnea species complex. Ecological Entomology 31, 1-11.

Chapman, J.W., Reynolds, D.R., Mouritsen, H., Hill, J.K., Riley, J.R., Sivell, D., Smith, A.D. \& Woiwod, I.P. (2008) Wind selection and drift compensation optimise migratory pathways in a high-flying moth. Current Biology 18, 514-518.

Chen, R.-L., Bao, X.-Z., Drake, V.A., Farrow, R.A., Wang, S.-Y., Sun, Y.-J. \& Zhai, B.-P. (1989) Radar observations of the spring migration into northeastern China of the oriental 
armyworm moth, Mythimna separata and other insects. Ecological Entomology 14, 149-162.

Chinery, M. (1993) Field Guide: Insects of Britain and Northern Europe (3rd edition). 320 pp. +60 colour plates. London, UK, HarperCollins.

Drake, V.A. (1984) The vertical distribution of macro-insects migrating in the nocturnal boundary layer: a radar study. Boundary-Layer Meteorology 28, 353-374.

Drake, V.A. \& Farrow, R.A. (1988) The influence of atmospheric structure and motions on insect migration. Annual Review of Entomology 33, 183-210.

Drake, V.A. \& Gatehouse, A.G. (Eds) (1995) Insect Migration: Tracking Resources through Space and Time. 478 pp. Cambridge, UK, Cambridge University Press.

Drake, V.A. \& Rochester, W.A. (1994) The formation of layer concentrations by migrating insects. pp. 411-414 in Proceedings of 21st Conference on Agricultural and Forest Meteorology11th Conference on Biometeorology, 7-11 March 1994, San Diego, California. American Meteorological Society, Boston, MA, USA.

Feng H.-Q., Wu, K.-M., Cheng, D.-F. \& Guo, Y.-Y. (2003) Radar observations of the autumn migration of the beet armyworm Spodoptera exigua (Lepidoptera: Noctuidae) and other moths in northern China. Bulletin of Entomological Research 93, 115-124.

Feng, H.-Q., Wu, K.-M., Cheng, D.-F. \& Guo, Y.-Y. (2004) Spring migration and summer dispersal of Loxostege sticticalis (Lepidoptera: Pyralidae) and other insects observed with radar in northern China. Environmental Entomology 33, 1253-1265.

Feng H.-Q., Wu, K.-M., Ni, Y.-X., Cheng, D.-F. \& Guo, Y.-Y. (2005) High altitude windborne transport of Helicoverpa armigera (Lepidoptera: Noctuidae) and other moths in mid summer in northern China. Journal of Insect Behavior 18, 335-349.

Fitt, G.P. (1989) The ecology of Heliothis species in relation to agroecosystems. Annual Review of Entomology 34, 17-52.

French, R.A. (1969) Migration of Laphygma exigua Hübner (Lepidoptera:Noctuidae) to the British Isles in relation to large-scale weather systems. Journal of Animal Ecology 38, 199-210.

Gatehouse, A.G. (1997) Behavior and ecological genetics of wind-borne migration by insects. Annual Review of Entomology 42, 475-502.

Geerts, B. \& Miao, Q. (2005) Airborne radar observations of the flight behavior of small insects in the atmospheric convective boundary layer. Environmental Entomology 34, 361-377.

Glick, P.A. (1939) The distribution of insects, spiders and mites in the air. 150 pp. Technical Bulletin of the US Department of Agriculture No. 673.

Hächler, M., Bloesch, B. \& Mittaz, C. (2002) Migration des lépidoptères nocturnes: observations au col du GrandSaint-Bernard. Revue Suisse d'Agriculture 34(3), 137-145.

Hill, J.K. \& Gatehouse, A.G. (1993) Phenotypic plasticity and geographical variation in the pre-reproductive period of Autographa gamma (Lepidoptera: Noctuidae) and its implications for migration in this species. Ecological Entomology 18, 39-46.

Howard, R.A. (1999) Possible migration of Noctua pronuba (L.) (Lepidoptera: Noctuidae) at Lizard Point, Cornwall. Entomologist's Gazette 50, 33-38.

Johnson, C.G. (1969) Migration and Dispersal of Insects by Flight. 763 pp. London, UK, Methuen.
Lewis, T. \& Taylor, L.R. (1964) Diurnal periodicity of flight by insects. Transactions of the Royal Entomological Society of London 116, 393-479.

Macaulay, E.D.M., Tatchell, G.M. \& Taylor, L.R. (1988) The Rothamsted Insect Survey 12-metre suction trap. Bulletin of Entomological Research 78, 121-129.

Maryon, R.H. (1997) The gravitational settling of particulates: towards a parameterisation for the 'NAME' dispersion model. Turbulence and Diffusion Note 244, Bracknell UK, Met Office (Public Met Services Research, PMSR).

Pedgley, D.E. (1982) Windborne Pests and Diseases: Meteorology of Airborne Organisms. 250 pp. Chichester, UK, Ellis Horwood.

Pedgley, D.E. (1993) Managing migratory insect pests-a review. International Journal of Pest Management 39, 3-12.

Reynolds, A.M., Reynolds, D.R. \& Riley, J.R. (2008) Does a 'turbophoretic' effect account for layer concentrations of insects migrating in the stable night-time atmosphere? Journal of the Royal Society - Interface 6, 87-95.

Reynolds, D.R., Chapman, J.W., Edwards, A.S., Smith, A.D., Wood, C.R., Barlow, J.F. \& Woiwod, I.P. (2005) Radar studies of the vertical distribution of insects migrating over southern Britain: the influence of temperature inversions on nocturnal layer concentrations. Bulletin of Entomological Research 95, 259-274.

Reynolds, D.R., Chapman, J.W. \& Harrington, R. (2006) The migration of insect vectors of plant and animal viruses. Advances in Virus Research 67, 453-517.

Reynolds, D.R., Chapman, J.W. \& Smith, A.D. (2008) A radar study of emigratory flight and layer formation by insects at dawn over southern Britain. Bulletin of Entomological Research 98, 35-52.

Riley, J.R., Reynolds, D.R., \& Farmery, M.J. (1983) Observations of the flight behaviour of the armyworm moth, Spodoptera exempta, at an emergence site using radar and infra-red optical techniques. Ecological Entomology 8, 395-418.

Showers, W.B. (1997) Migration ecology of the black cutworm. Annual Review of Entomology 42, 393-425.

Smith, A.D., Riley, J.R. \& Gregory, R.D. (1993) A method for routine monitoring of the aerial migration of insects by using a vertical-looking radar. Philosophical Transactions of the Royal Society, Series B 340, 393-404.

Smith, A.D., Reynolds, D.R. \& Riley, J.R. (2000) The use of vertical-looking radar to continuously monitor the insect fauna flying at altitude over southern England. Bulletin of Entomological Research 90, 265-277.

Sparks, T.H., Dennis, R.L.H., Croxton, P.J. \& Cade, M. (2007) Increased migration of Lepidoptera linked to climate change. European Journal of Entomology 104, 139-143.

Stull, R.B. (1997) An Introduction to Boundary Layer Meteorology. 666 pp. Dordrecht, The Netherlands, Kluwer Academic Publishers.

Taylor, L.R. (1974) Insect migration, flight periodicity and the boundary layer. Journal of Animal Ecology 43, 225-238.

Taylor, L.R. \& Carter, C.I. (1961) The analysis of numbers and distribution in an aerial population of Macrolepidoptera. Transactions of the Royal Entomological Society of London 113, 369-386.

Williams, C.B. (1948) The Rothamsted light trap. Proceedings of the Royal Entomological Society of London, Series A 23, 80-85.

Woiwod, I.P. \& Harrington, R. (1994) Flying in the face of change: the Rothamsted Insect Survey. pp. 321-342 in 
Leigh, R.A. \& Johnson, A.E. (Eds) Long-term Experiments in Agricultural and Ecological Sciences. Wallingford, UK, CAB International.

Wood, C.R. (2007) The biometeorology of high-altitude insect layers. PhD thesis, The University of Reading, UK.

Wood, C.R., Chapman, J.W., Reynolds, D.R., Barlow, J.F., Smith, A.D. \& Woiwod, I.P. (2006) The influence of the atmospheric boundary layer on nocturnal layers of moths migrating over southern Britain. International Journal of Biometeorology 50, 193-204.

Wolf, W.W., Westbrook, J.K., Raulston, J., Pair, S.D. \& Hobbs, S.E. (1990) Recent airborne radar observations of migrant pests in the United States. Philosophical Transactions of the Royal Society, Series B 328, 619-630. 